\title{
ERRATUM
}

\section{Integrating HIV Prevention Activities into the HIV Medical Care Setting: A Report from the NYC HIV Centers Consortium}

Tracey E. Wilson, David Vlahov, Stephen Crystal, Judith Absalon, Susan J. Klein, Robert H. Remien, and Bruce Agins

The name of the sixth coauthor of this article is Robert H. Remien (not Robert H. Remein). 